\title{
Lidar Measurements of Wind Flow through a Rotor-swept Area in Tehachapi Pass
}

\author{
Kai Zhou, Ronald Calhoun* \\ Mechanical \& Aerospace Engineering, Arizona State University, Tempe, AZ85287-9809, USA \\ *Email: Ronald.Calhoun@asu.edu
}

\section{INTRODUCTION}

Retrieval of wind fields from a single-Doppler lidar with small azimuthal sectors is challenging. Both simpler retrieval algorithms such as Velocity Azimuth Display (VAD) or Volume Velocity Processing (VVP), and more sophisticated techniques such as Four Dimensional Variational Analysis (4DVAR) using VAD for mean velocities have limitations on small sectors of data. Narrow datasets may result in non-orthogonality and collinearity of basis functions, which causes numerical instability. Although careful inspection of data can reduce the instability, large conditional number computations which use data over small sectors may make results unacceptable [1].

Since estimates of wind velocities retrieved from single Doppler lidar over limited sectors may be of interest (i.e., winds through a single wind turbine or wakes behind buildings), a method to retrieve wind velocity in these situations would be valuable. In this work, we experiment with an algorithm which is able to provide these velocity estimates under the assumption that the wind direction is relatively unchanging or varies linearly over a larger sector, and quasi-2D ridge can have a tendency to homogenize wind direction. The wind direction of the larger neighborhood is obtained from a sectorVAD-like method while magnitudes are allowed to vary fully locally.

\section{EXPERIMENTAL SETUP}

Data presented in the paper were collected during a field experiment in Tehachapi Pass in California during the period from February $21^{\text {st }}$ to $23^{\text {rd }}, 2015$. The objective of the campaign was to capture the behavior of the wind flowing through the rotor-swept area of a wind turbine. The measured wind field will be used as a forcing function in a wind farm simulation using data assimilation.
According to the prevailing wind direction of Tehachapi Pass, the lidar was placed northwest (upwind) of a turbine with distance of $560 \mathrm{~m}$ at $35^{\circ} 5^{\prime} 39.00^{\prime \prime} \mathrm{N}, 118^{\circ} 20^{\prime} 27.60^{\prime \prime} \mathrm{W}$, with the goal of capturing the wake downwind of the turbine.

The lidar is a $1.6 \mu \mathrm{m}$ WindTracer Doppler with a pulse repetition frequency of $750 \mathrm{~Hz}$. It was configured to average over 100 pulses resulting in a product rate of $7.5 \mathrm{~Hz}$. The rangegate length for the lidar was set at $100 \mathrm{~m}$.

A "stack" of Plan Position Indicator (PPI) scans was executed at elevation angles ranging from $5.5 \mathrm{deg}$ to $10.6 \mathrm{deg}$ with step of $0.255 \mathrm{deg}$. In each PPI scan, the lidar scanned with different rates in the three regions (shown in Fig. 1) with scanning rates of $5 \mathrm{deg} / \mathrm{sec}$ in region I (119.9 deg to $130.4 \mathrm{deg}$, measured clockwise from north) and region III (136.4 deg to $146.4 \mathrm{deg}$ ), and 0.5 $\mathrm{deg} / \mathrm{sec}$ in region II (130.4 deg to $136.4 \mathrm{deg})$. Region II corresponded to the rotor-swept area. The three regions cover not only the rotor-swept area but also the space in the vicinity as shown in Fig. 1. With this scanning pattern, region I and III have fewer data points than the region II. Each stack of PPI took approximately 1 minute.

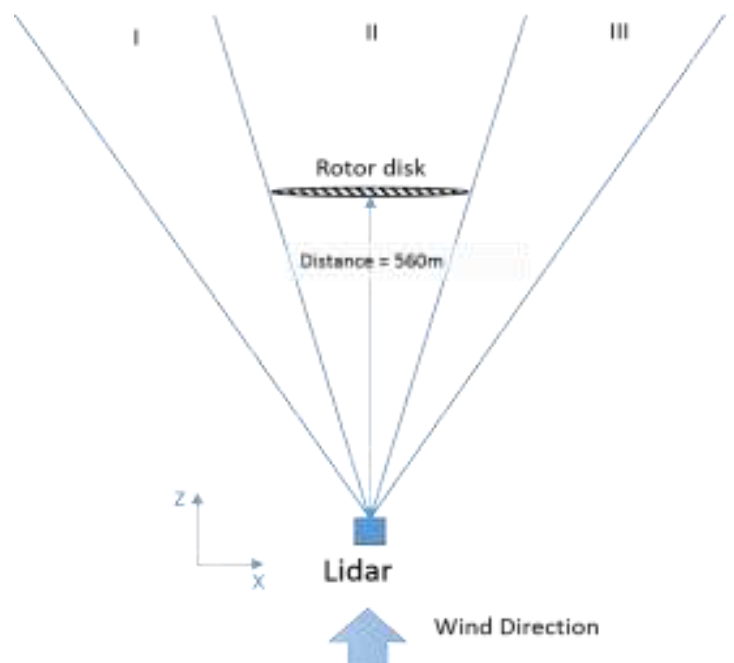

Fig.1 Top view of the scanning pattern 


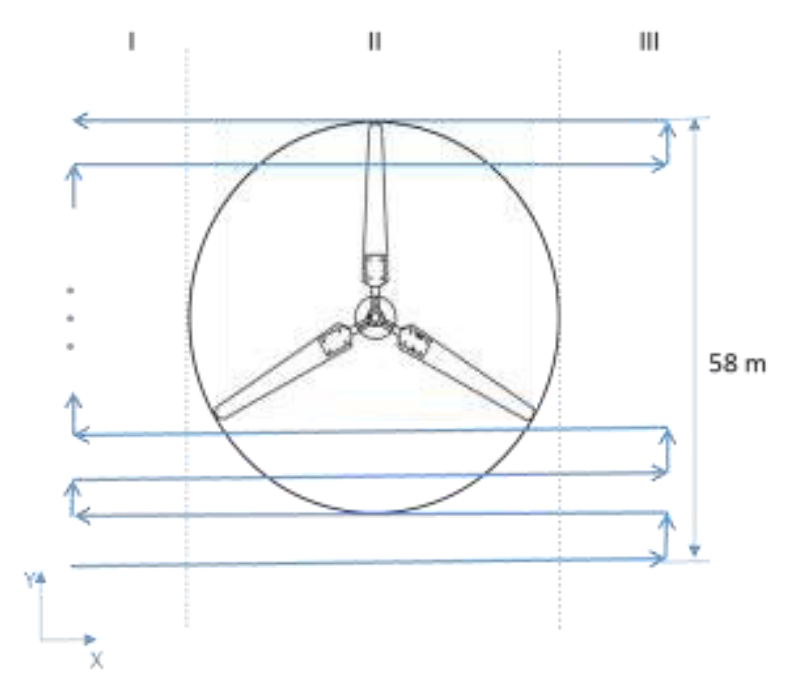

Fig.2 Front view of the scanning pattern

\section{ALGORITHM}

This algorithm is based on the assumption that the change of the magnitude of wind velocity in region II due to the rotor is more important than that due to the variation of wind direction so that the wind direction in each range gate in region II is treated as uniform or varying linearly over each elevation level. We assume that the wind direction in the rotor-swept area can be reasonably estimated using a sector-VAD fit over the larger sector formed from regions I and III. Note typical wind turbine operation presumes that efficient operation can be obtained with the yaw tracking only running-means of wind direction. Under these assumptions and the relatively rapid scanning of sectors I and III, the wind direction in the rotor-swept area can be obtained from observations in region I and III without large increases in cost, and the data points measured over the wider sector are sufficiently dispersed for the viability of sector-VAD method.

As given in [2], the equation for VAD is given as:

$$
V_{r}=\left[V_{x} \cos (\beta) V_{y} \cos (\beta)\right] \cdot[\sin (a) \cos (a)]^{\mathrm{T}}(1)
$$

where $V_{r}$ is the lidar radial velocity observation; $[\sin (a) \cos (a)]^{\mathrm{T}}$ is the basis function matrix and $\left[V_{x} \cos (\beta) V_{y} \cos (\beta)\right]$ is the parameter vector; $\alpha$ and $\beta$ are the azimuth and the elevation angles, respectively; $V_{x}$ and $V_{y}$ are the velocity in the $x$ and $y$ directions, respectively. Knowing the radial velocity and the look direction, uniform wind direction at each range gate can be obtained from $V_{x}$ and $V_{y}$ computed by least square regression to equation (1) with careful outlier rejection suggested by Boccippio [1].

In region II, as the radial velocity is the projection of wind vector on the look direction of the lidar, the wind speed $|\mathbf{V}|$ can be solved from the equation (2)

$$
V_{r}=|\mathbf{V}| \cdot \mathbf{r} \cdot \mathbf{L}
$$

Here, $V_{r}$ is the radial velocity in region II, $\mathbf{r}$ is a unit wind direction vector calculated in region I and III, $\mathbf{L}$ is a unit look direction vector of the lidar which is a function of azimuth and elevation angles. Therefore, the mean velocity vector $\mathbf{V}=|\mathbf{V}| \cdot \mathbf{r}$ in the rotor-swept area is retrieved at each data point.

\section{RESULTS}

The slow scanning rate gives good spatial resolutions in the rotor-swept area. The horizontal resolution between successive measurements is approximately from $0.7 \mathrm{~m}$ at the turbine, to $1 \mathrm{~m}$ at five diameters (5D), $290 \mathrm{~m}$ downstream the turbine, due to diverging beams. The vertical resolution between successive elevation angles is approximately from $2.5 \mathrm{~m}$ at the turbine to $3.8 \mathrm{~m}$ at $5 \mathrm{D}$. The radial (along the beam, not the rotor) resolution is $100 \mathrm{~m}$ due to the range-gate length. The fast scanning rate in region I and III consumes little time, resulting in high temporal resolution without reducing the quality of the results.

Two examples of radial velocity measured at 19:33:43 UTC (11:33:43 local time) on Feb.21, 2015 at elevation angle $8.05 \mathrm{deg}$, the angle for hub height and 8.56 deg are shown in Fig. $3 \mathrm{a}$ and Fig. 4a. The black line indicates the wind turbine being scanned. White regions in Fig. 3 and Fig. 4 are missing or contaminated data. However, the overall velocity deficits behind the turbine are clearly observed in the plots. Resulting retrieved wind speeds from the two datasets are shown in Fig. $3 \mathrm{~b}$ and Fig.4b, respectively. The retrieved wind velocities apparently recover the velocity deficit in the wakes. 


\section{CONCLUSIONS AND FUTURE WORK}

A new algorithm of retrieving wind velocity from small sectors of lidar observations is proposed. It is demonstrated by retrieving the wind flow through a rotor-swept area of a wind turbine located in Tehachapi Pass. Preliminary results show the retrieval method appears to recover the wind field at least for the current cases.

The given assumptions clearly have limitations, but may have usefulness for certain applied problems such as wind flowing through a rotor swept area of a wind turbine. Future work will be to test the level of error involved in these assumptions as a function of conditions. Verification of the algorithm with more experimental observations under various wind conditions, and with numerical simulation of wind field with a single wind turbine is another possibility for further study.

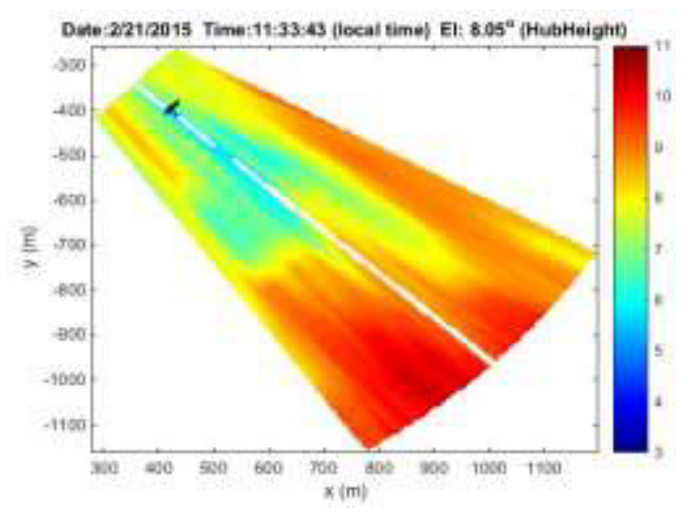

Fig.3a Radial velocity from the PPI scan at elevation angle of $8.05 \mathrm{deg}$

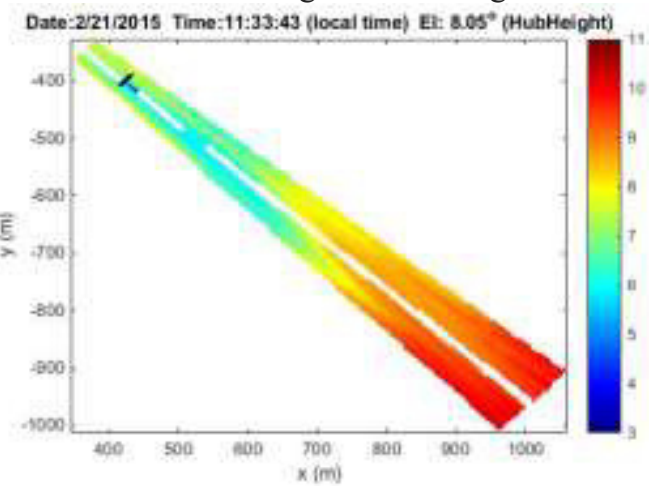

Fig.3b Magnitude of retrieved velocity vector from the PPI scan at $8.05 \mathrm{deg}$

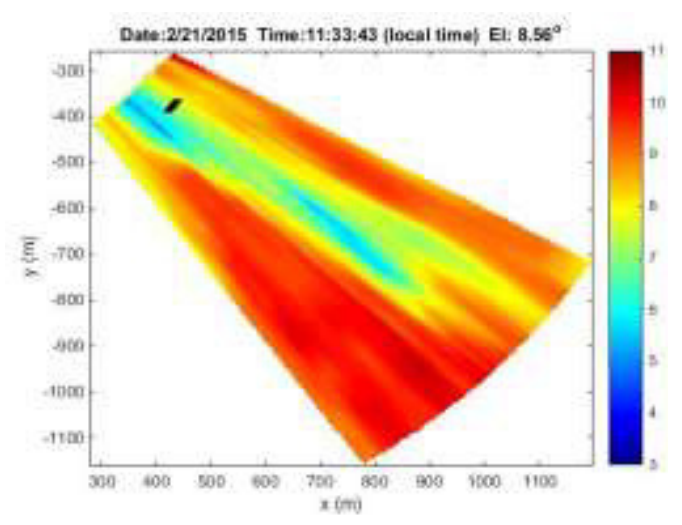

Fig.4a Same as Fig. 3a, but at $8.65 \mathrm{deg}$

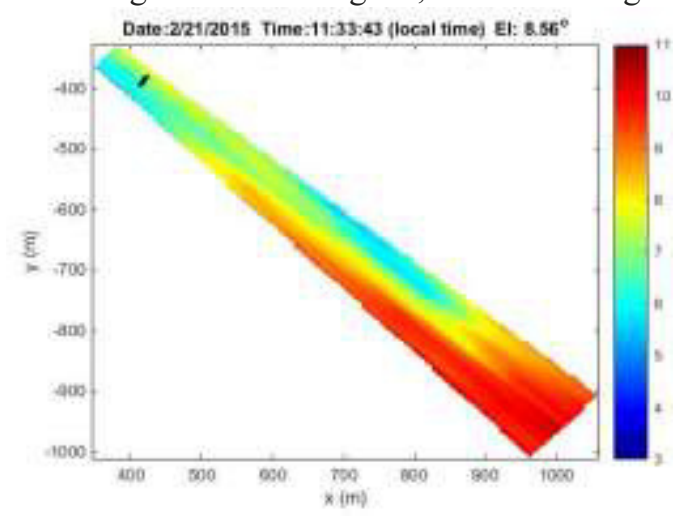

Fig.4b Same as Fig. 3b, but at 8.65 deg

\section{ACKNOWLEDGEMENT}

Funding from Electric Power Research Institute (EPRI, program manager Dr. Aidan Tuohy) and NSF (program manager Dr. Gregory Rorrer) are gratefully acknowledged (grants 00-10001389 and 1335868, respectively). We would especially like to thank WindLand for site permissions and help with facility setup. Valuable guidance was provided by James Blatchford of CAISO.

\section{REFERENCES}

[1] Boccippio, D. J. 1995: A diagnostic analysis of the VVP single-Doppler retrieval technique, Journal of Atmospheric and Oceanic technology, 12(2), 230-248.

[2] Browning, K. A., \& Wexler, R. 1968: The determination of kinematic properties of a wind field using Doppler radar. Journal of Applied Meteorology, 7(1), 105-113. 